\title{
GALDÓS, FLÂNEUR Y PEREGRINO POR INGLATERRA: LA CASA DE SHAKESPEARE ${ }^{1}$
}

\author{
$\mathrm{M}^{\mathrm{a}}$. de los Ángeles AyALA \\ Universidad de Alicante \\ Grupo de Estudios Galdosianos (GREGAL)
}

\section{RESUMEN}

Viaje físico y emocional de Pérez Galdós a Straford, ciudad en la que nació y murió su admirado William Shakespeare. Crónica de viaje en la que el espacio urbano y la literatura se hermanan a través del genio universal inglés.

Palabras clave: Siglo XIX, Pérez Galdós, La casa de Shakespeare, crónica de viaje

\section{ABSTRACT}

The physical and emotional journey of Pérez Galdós to Stratford, the birthplace and final resting place of William Shakespeare, who he admired. The travel chronicles in which urban space and literature unite in Shakespeare.

Key words: 19th century, Pérez Galdós, La casa de Shakespeare, travel chronicles

La vocación viajera de Benito Pérez Galdós es una manifestación clara y evidente de esa inclinación que define el quehacer literario y la propia personalidad del escritor: la observación minuciosa del entorno real. La confluencia de curiosidad, observación y reflexión será la base perfecta de su creación literaria. El propio escritor confesará en innumerables ocasiones su afán por escudriñar todos los rincones de las ciudades en las que vive o visita. Sirva como botón de muestra los párrafos que en sus incompletas memorias recogen

1. El presente trabajo se inserta en el proyecto de investigación I+D del Ministerio de Innovación y Tecnología «Edición y estudios críticos de la obra literaria de Benito Pérez Galdós» (FFI2010-15995). 
las primeras vivencias a su llegada a Madrid, cuando en vez de acudir a la Universidad «ganduleaba por las calles, plazas y callejas, gozando de observar la vida bulliciosa de esta ingente y abigarrada capital [...] mis días se me iban en flanear por las calles» (1873: 1430) o cuando en 1867 emprende su primer viaje a París para visitar la Exposición Universal, recinto que no parece terminar de entusiasmarle, pues Galdós se interesa más por escudriñar la ciudad que, en aquel tiempo, era considerada la metrópoli del mundo civilizado:

Devorado por febril curiosidad, en París pasaba yo el día entero calle arriba, calle abajo, en compañía de un plano, estudiando la muchedumbre de sus monumentos, confundido entre el gentío cosmopolita que por todas partes bullía. A la semana de este ajetreo ya conocía París como si éste fuera un Madrid diez veces mayor [...] El resto de mi tiempo, en aquel verano, lo empleaba paseándome, observando la transformación de la gran Lutecia, iniciada por el Segundo Imperio. Los Bulevares Haussmann, Malesherbes, Magenta y otros de la orilla derecha, así como los de Saint Germain y Saint Michel en la otra orilla izquierda, estaban en construcción» (1873: 1431-1432).

A finales de 1882, en el mes de octubre, recibe una carta de un viejo amigo, José Alcalá Galiano ${ }^{2}$, recién incorporado como cónsul de España en Newcastle on Tyne, proponiéndole que le visite el próximo verano para realizar «una excursión novelesca a Escocia, teatro de las bellas novelas del Galdós inglés, Walter Scott $»^{3}$. Proposición que debió acoger con gran interés, pues, después de acabar la redacción en el mes de mayo de 1883 de su novela El doctor Centeno, le confirma por carta que se encontrará con él en Londres ese mismo verano, experiencia de la que apenas tenemos datos, pues las escasas referencias que existen las hallamos en las desmemoriadas memorias galdosianas. Allí ambos amigos, tal como supone Ortiz Armengol (1981; 1996: 375), debieron recorrer todos los rincones londinenses, con un plano en la mano, tal como le gustaba a Galdós, pues en la biblioteca particular del escritor, entre otros

2. La amistad entre José Alcalá Galiano y Fernández de las Peñas y Pérez Galdós se remontaba a los primeros años de estancia de D. Benito en la capital de España, cuando ambos ocupaban cargos honoríficos en el Ateneo madrileño presidido por D. Juan Valera. Amistad y también admiración por la creación galdosiana, como se demuestra en la reseña crítica que José Alcalá publica el 13 de mayo de 1971 en La Revista de España, $\mathrm{n}^{\circ} 77$, pp.148-158, a raíz de la publicación de La Fontana de Oro o en su adhesión a los banquetes organizados en honor del novelista por Palacio Valdés, Clarín, Sellés, entre otros, en marzo de 1883 en Madrid (Franco Rodríguez, s.a.: 192-193; Berkowitz, 1989: 163-172). Especialmente relevante para conocer las relaciones entre José Alcalá Galiano y Benito Pérez Galdós es el opúsculo no venal publicado por Ortiz -Armengol (1981).

3. Carta fechada el 24 de octubre de 1882. De la Nuez y Schraibman (1967: 363) catalogan ochenta y seis cartas de José Alcalá dirigidas a Benito Pérez Galdós. Epístolas que en la actualidad se pueden consultar en el Archivo Epistolar digitalizado por la Casa-Museo Pérez Galdós. www.lascartasdeperezgaldos.com. 
muchos documentos, se conserva un plano desplegable de Londres, con una guía de viajeros, de $1882^{4}$. El propio Galdós da cuenta en sus Memorias de la entrañable amistad que le unió a José Alcalá y de cómo se convierte en compañero inestimable de sus viajes por Europa, recorridos que se iniciaban generalmente tras pasar Galdós unos días gozando de la dulce hospitalidad inglesa en la casa del Consulado donde residía su amigo, felizmente casado con una dama irlandesa, tan bella como ilustrada, en el sentir de Galdós. Amistad que también se manifiesta en los afectivos párrafos que hallamos en la sección Cartas que publica en La Prensa de Buenos Aires durante los meses de octubre y noviembre de 1887 al comentar su viaje por Holanda, Dinamarca y Alemania llevado a cabo durante los meses de verano. En ellas, tras calificarlo de poeta eminentísimo, se lamenta que los servicios que presta a España como cónsul en Newcastle on Tyne lo alejen del terreno de las letras ${ }^{5}$. Galdós habla de su amigo en los siguientes términos:
Alcalá Galiano es un entendimiento general y flexible. Posee tal variedad de conocimientos y tanta gracia y originalidad para expresar sus ideas, que su conversación es encantadora y su compañía inapreciable. Sus composiciones poéticas se distinguen por la osadía de sus pensamientos y el vigor con que los expresa. Además es políglota: habla a la perfección tres o cuatro lenguas de las más usuales, y conoce y recita de memoria los poetas de todos los países. Pocos hombres conozco que tengan un trato más ameno. A su lado se pasan sin sentido las horas [...] no olvidaré nunca las horas que hemos pa- sado juntos, discurriendo por las calles de Amsterdam, Berlín, Copenhague o Hamburgo, haciendo críticas más o menos sesudas y formales de lo que vemos y comunicándonos nuestras impresiones con la confianza que inspira una amistad antigua y entrañable como la nuestra (Shoemaker, 1973: 277).

El único relato de viaje por tierras inglesas que recogió en volumen Galdós fue el referido a su excusión a la ciudad natal de Shakesperare, aunque bien es verdad que en sus Memorias y en las Cartas enviadas a La Prensa alude con insistencia a distintas excursiones por Gran Bretaña. Especial atención concede a las ciudades de Edimburgo y Londres en sus Memorias. La primera, descrita desde una doble óptica. Por un lado, como importante centro cultural, pues Edimburgo es para el escritor «la ciudad de las imprentas, emporio de las librerías y del saber académico» (1973: 1465), actividad económica y

4. Se trata del Plano de Londres, de James Raynolds and Sons», 17 hojas, $53 X 77 \mathrm{~cm}$., catalogado por De la Nuez (1990: 230) con la signatura XI, 2364.

5. José Alcalá Galiano (1843-1919), además de diplomático, fue autor de zarzuelas, novelas, cuentos y un extenso corpus poético recogido en gran medida en Estereoscopio social (1872), colección de versos satíricos y humorísticos que cuenta con un prólogo escritor por el propio Pérez Galdós. Especialmente relevantes son, según el criterio de algunos estudiosos, como Menéndez Pelayo, sus traducciones de los poemas de Lord Byron. 
cultural impulsada por su magnífica Universidad. Por otro lado, el Edimburgo que Galdós descubre en su acelerada visita es la ciudad monumental, con sus edificios y espléndidas casas, sus museos, hoteles, estación de ferrocarril y, como no podía ser de otra forma, destaca sobre todos ellos el monumento dedicado a Walter Scott en Princess-Street, la calle principal de Edimburgo. La visita a la residencia de los últimos reyes de Escocia, el Palacio de Holyrrodd, con una mención al drama de Schiller María Estuardo y una larga digresión sobre la historia de esta reina, pone fin a esta sucinta descripción urbana. Mayor relevancia y significado tienen, sin duda, los dos lugares londinenses descritos por Galdós en sus Memorias. Adoptando el tono propio de clara difusión periodística describe someramente el itinerario que sigue desde Trafalgar Square hasta llegar a orillas del Támesis donde se encuentra el Parlamento, edificio que alberga «a la institución más estable y grandiosa de la vieja Inglaterra» (1973: 1467). Galdós destaca las dimensiones inmensas de este edificio, con su corpulenta y elevadísima torre. Subraya la grandiosidad de sus dimensiones y el lujo de sus salones, magnificencia del edificio acorde al papel que representa en la historia y la vida de la nación, pues «allí reside la verdadera majestad, la soberanía efectiva de la nación» (1973: 1465). Galdós en estas páginas no duda en mostrar su admiración por el sistema parlamentario inglés, que «debiera ser ejemplo de todo el mundo» (1973: 1465). Al lado de esas referencias de carácter político aparece su admiración por el arraigado orgullo británico por su historia, por el recuerdo de sus grandes hombres y la glorificación de sus hechos más célebres, características que se materializan, desde su punto de vista, en el recinto de la Abadía de Westminster. Templo donde los dioses se codean con los mortales, pues en sus capillas se encuentran enterrados todos los reyes, reinas, príncipes y caballeros que han ennoblecido la patria. Allí junto a las sepulturas de científicos de la talla de Newton y Darwin, se encuentra la sala denominada el Rincón de los poetas, el espacio físico que más emociona a Galdós, pues acoge «la brillantísima pléyade de poetas, novelistas, historiadores, críticos, músicos, actores, etc., que en siglos diferentes han brillado en el espacio infinito del arte británico [...] Allí están los profetas, apóstoles, mártires, los elegidos, en fin, merecedores de la inmortalidad» (1973: 1468). Entre los nombres que Galdós destaca están Macaulay, Thackeray, Haendel, el músico que los ingleses consideran como suyo, aunque naciera en Alemania, Goldsmith, Pope, Addison, Chaucer, Thomson, Prior, Campell, el afamado comediante Garrick, Milton, Spencer... y destacando sobre todos ellos, sus admirados Shakespeare y Dickens. Galdós dedica un significativo fragmento a la descripción del espacio físico que ocupa una sepultura reciente, pues en ella 
[...] trazado al parecer con carácter provisional, leí esta inscripción: Dickens. En efecto, el gran novelador inglés había muerto poco antes. Como este fue siempre un santo de mi devoción más viva, contemplé aquel nombre con cierto arrobamiento místico. Consideraba yo a Carlos Dickens como mi maestro más amado (1973: 1468) ${ }^{6}$.

Galdós en sus Memorias destaca estos dos edificios, el Parlamento y la Abadía de Westminster, dos lugares, sin duda, emblemáticos y caracterizadores de la sociedad inglesa, pero que para el escritor poseen un significado especial, pues ponen de manifiesto dos de las características esenciales del pueblo inglés: su desarrollado sistema parlamentario y la glorificación de los grandes hombres que han contribuido con sus obras al engrandecimiento de su patria.

Como es habitual en las mencionadas Memorias los datos son en ocasiones bastantes confusos. Según este texto, tras su viaje por los Países Bajos, Alemania y Dinamarca en 1887, Galdós dejó a José Alcalá en Newcastle on Tyne, prosiguiendo su visita a Edimburgo y Birmingham. De esta última ciudad partiría hacia la patria de Shakespeare: Stratford-on-Avon (1973: 1442). No obstante, en páginas posteriores de las Memorias, Galdós contradice en parte los datos ofrecidos con anterioridad, pues tras confesar que no recuerda el año concreto, rememora su viaje a Edimburgo acompañado de José Alcalá, primera jornada de su proyectada excursión por tierras escocesas (1973: 1464-1466). Sin embargo, por obligaciones apremiantes del Consulado, José Alcalá se vio impelido a regresar a Newcastle, renunciando a visitar la región de los lagos «cuyas poéticas leyendas enardecían vivamente nuestra imaginación» (1973: 1465) Según Galdós, camino de Inglaterra, decide no demorar su deseado viaje a Stratford, aunque para ello se vea obligado a prescindir de la compañía de su buen amigo. La visita a la casa natal de Shakespeare se realizó en septiembre de 1889 , tal como se constata en las crónicas enviadas a La Prensa entre noviembre del citado año y enero de $1890^{7}$. Relato de viaje

6. Aunque Dickens había expresado su deseo de ser enterado en la catedral de Rochester, próxima a su domicilio de Gud Hill, Kent, su familia cedió a la fuerte presión pública que, liderada por The Times, exigía que lo fuera en la Abadía de Westminster. La ceremonia privada tuvo lugar el 14 de junio de 1870.

7. En la primera Carta enviada a La Prensa durante los meses mencionados de 1889 aparece el siguiente sumario: «Volvamos a Inglaterra.- ¿Por dónde se va a Stratford? - El «bradshaw» y la confusión de las vías férreas.- Cómo se viaja en Inglaterra.- Birmingham.Multiplicidad de productos industriales.- La estación central.- Atravesando el «Warkick Shire.- Comarca sin industria.- Apacibilidad del territorio.- Stratford. Los hoteles y sus habitantes con emblema dramático.- Imaginería shakesperiana.- En la puerta de la casa natal.» (Shoemaker, 1973: 380). En las correspondientes a 1890 el sumario es el siguiente: «La casa natal.- El retrato que pasa por auténtico.- El Museo shakesperiano.- «New Place».- La casa y el arbol derribados por un enemigo de las visitas.- «Holy Trinity 
configurado en su redacción definitiva, según el propio Galdós, en 1890, aunque habrá que esperar hasta 1894 (mayo-junio) para verlo publicado en el periódico El Imparcial. Crónica recogida también en sus volúmenes La casa de Shakespeare (s.a. [1894]) y Memoranda (1906). ${ }^{8}$

A diferencia de los párrafos alusivos a su estancia en Edimburgo que hemos mencionado, en este relato de viaje Galdós se aleja de la mera descripción pintoresca, para ofrecer a sus lectores unas páginas más animadas, donde se transmite con total naturalidad el estado emocional del escritor ante la ciudad que es cuna y sepultura del gran poeta inglés. Galdós no olvida por ello que está escribiendo una crónica, de ahí que elija la clásica estructura del relato de viaje decimonónico, en el que el escritor comenta las anécdotas sucedidas en el transcurso del mismo, a la vez que enumera y describe los lugares y monumentos que va descubriendo o visitando. La crónica se estructura en cuatro apartados: «¿Por donde voy a Stratford? La estación de Birmingham», «Stratford al fin: Shakespeare's Hotel», «La casa»y «La tumba», distribución material que guarda estrecha relación con la turbación íntima del escritor, pues a medida que se va produciendo el acercamiento físico a la casa y tumba de Shakespeare la emoción palpita en estas páginas con mayor intensidad.

En el primero de ellos, el cronista, con soltura y gran sentido de humor, da cuenta de las dificultades que envolvieron su proyectado desplazamiento de Londres a Stratford, pues si bien es verdad que alaba el desarrollo insuperable que la red ferroviaria ha alcanzado en estas tierras, esa misma amplitud complica, como él mismo tiene ocasión de comprobar, la elección del itinerario adecuado para desplazarse a un punto concreto de la geografía inglesa alejado de las tres grandes líneas que, partiendo de Londres, cruzan toda la isla ${ }^{9}$. Galdós se demora en la descripción del trasiego de viajeros y del mismo

Church».- La tumba de Shakespeare.- Una iglesia protestante que parece católica.- El retablo de Shakespeare y su imagen.- Inscripciones en latín y en inglés.- Tumba de Ana Hathaway.- La «Grammar School».- La Torre del Reloj y el «Shakespeare Memorial».Teatro, museo, biblioteca y jardines.- Conclusión de la visita.- La vida de Shakespeare. (Shoemaker: 1973: 3198-390).

8. Recientemente la editorial madrileña Rey Lear ha publicado de nuevo el texto galdosiano.

9. De ahí que, con gran sentido del humor, muestre su satisfacción por haber conseguido acomodarse en el tren adecuado: «Muchos empleados no saben cual es el camino de Stratford, y lo más que hacen es informar con incierto laconismo: «Es de la otra parte». Y recorra usted otra vez los puentes que comunican las inmensas naves por encima de las vías. Después pase usted por un túnel abierto debajo de otras, hasta llegar a las plataformas del costado Sur, y allí, échese a correr a lo largo del interminable andén [...] Gracias a Dios, ya tengo en la mano el billete para Stratford; tomo asiento en un coche; el tren marcha. Mil y mil veces gracias al Señor» [1894: 9-10]. 
movimiento ferroviario, símbolo en su época de la modernidad y el progreso de un país:

Verdadera maravilla de la ciencia y de la industria es la muchedumbre de trenes que ponen en movimiento todos los días de la semana, menos los domingos, las compañías antes citadas [ «North-Western», «Midland» $\mathrm{y}$ «GreatNorthern»], y además las del «Great Western» y «Great Eastern», y la fácil exactitud con que las estaciones de empalme dan paso a tan enorme material rodante sin confusión ni retraso. La velocidad, acortando distancias, desarrolla en aquel país hasta tal punto la afición a los viajes, que toda la población inglesa parece estar en constante movimiento. Se viaja por negocio, por hacer visitas, por hablar con un amigo, por ir de compras a una ciudad próxima o lejana, por pasear y hacer ganas de comer (1894: 8). ${ }^{10}$

Galdós opta por dirigirse a Birmingham y desde allí, tras el consiguiente y engorroso trámite de averiguar qué tren es el más adecuado para realizar el trasbordo y obtener un nuevo billete, desplazarse a Stratford. Tarea complicada, pues la estación de Birmingham se describe como hervidero de personas y trenes. El trayecto ferroviario hacia Birmingham le pone en contacto con una de las zonas más industriales de Inglaterra. El paisaje, salpicado de chimeneas humeantes, manifiesta el poderío industrial de la comarca de Hallamshire, donde se ubican Sheffield, la metrópoli del cuchillo, y Birmingham, «ciudad populosa, una de las más grandes, ricas y trabajadoras de Inglaterra. Un poco más alegre que Manchester, se le parece en la animación febril de sus calles, en la negrura de sus soberbios edificios, y en la muchedumbre y variedad de establecimientos industriales» (1894: 8).

La segunda parte del relato dirige al lector hacia una nueva zona geográfica camino de Stratford. Desde los ventanales del tren el escritor observa atento el paisaje rural y urbanístico que se ofrece a sus ojos:

Han desaparecido las chimeneas, han huido aquellos fantasmas escuetos que se envuelven en el humo que vomitan, y que agobian el espíritu del viajero con su negrura satánica. Penetro en un país risueño, más agrícola que industrial, impregnado de amenidad campestre. No más fábricas, no más industria. La negra pesadilla se disuelve, y el humo, que todo lo entristece, se va quedando atrás (1894: 10).

Galdós fija su atención en la poética campiña, escudriña el castillo de Warwick y al pasar por las inmediaciones de las célebres ruinas del castillo de Kenilworth, no puede evitar recordar la afamada novela de Walter Scott titulada, precisamente, con este mismo nombre. No obstante, Galdós no se detiene en

10. En el presente trabajo citamos por la edición llevada a cabo por el librero Antonio López [1894].

Anales, 24, 2012, pp. 181-193 
la descripción de estos viejos vestigios del esplendor británico, pues su viaje, peregrinación emocional, se encamina hacia el lugar que acoge la memoria del inmortal dramático:

Omito la descripción de esas hermosas ruinas, así como la del castillo de Warwick, que me apartaría de mi objeto, y sigo en busca de la casa del poeta. ¡Kemilworth, Leicester, Isabel! Todo esto ha pasado, mientras que Shakespeare vivirá eternamente, y su humilde morada despertará más curiosidad e interés que todos los palacios de príncipes y magnates» (1894: 11).

La realidad de Stratford no desilusiona a Galdós, sino que por el contrario le sumerge en una atmósfera cálida, humana, anclada en el tiempo, pero a su vez atada al presente. Stratford es una localidad de diez mil habitantes, que respira el aire campestre, pero que disfruta de una organización social idéntica a la de una gran ciudad, es un pueblo «donde las leyes reciben el apoyo de la sanción impuesta por las costumbres» (1894: 15); Galdós se admira de encontrar tiendas tan bellas como las de Londres y comprueba que los sujetos que pasean por sus calles tienen el aspecto mismo de la burguesía londinense. El bienestar, la comodidad, la medianía placentera y sin pretensiones son los elementos que configuran Stratford: «es algo como el olor a ropa planchada que brota de la patriarcal alacena en esas casas de familia, más bien de campo que de ciudad, donde reina el orden tradicional y la economía que se resuelve en positiva riqueza» (1894: 16). Tranquilidad, armonía que no impide que la imaginación del viajero permanezca en constante ebullición, pues

[...] se lanza a los espacios ideales, representándose el tiempo en que vivía la eximia persona cuya sombra perseguimos en aquella apacible y poética localidad. No podemos separar al habitante de la morada, y nos empeñamos en trasladar ésta a los tiempos de aquél, o en modernizar al poeta para hacerle discurrir con nosotros por las calles, hoy alumbradas con gas, de su querida y placentera villa (1894: 12).

Galdós dejará volar su imaginación, ya que todo en Stratford parece confabularse en el mundo literario de Shakespeare, desde sus principales calles, hasta el propio hotel donde el novelista pernocta dos noches: «Shakespeare's Hotel $»^{11}$ : Establecimiento que se caracteriza porque todas su habitaciones llevan el nombre de títulos de los dramas del poeta: «El que a mí me tocó se denominaba «Love's Labours Lost», y la derecha mano vi «Hamlet», y más allá, en el fondo de un corredor oscuro y siniestro, «Macbeth» (1894:12). Atmós-

11. Galdós también incluye en su relación la existencia del «Red Hotel», establecimiento que alcanzó celebridad porque en él escribió Washington Irving sus impresiones sobre Stratford. 
fera poética, literaria a la que el propio dueño del hotel contribuye al haber llenado de cuadros, estampas y grabados alusivos a los dramas del poeta todas las paredes del confortable establecimiento, de manera que el viajero que pasa la noche allí se ve acosado por la turba de ilustres fantasmas:

Se los encuentra en su alcoba, en el comedor, y hasta en el cuarto de baño. Aquí «Lady Macbeth» lavándose la mano; más allá «Catalina de Aragón» reclamando sus derechos de reina y esposa, o el «Rey Lear», de luenga barba, echando maldiciones contra el cielo y la tierra. Por otra parte el fiero «Gloucester», de horrible catadura; el vividor «Falstaff», panzudo y dicharachero; más lejos el judío «Shylock» ante el tribunal presidido por la espiritual «Porcia». No faltan Antonio discurriendo ante el cadáver de César, ni «Kaliban» $\mathrm{y}$ «Ariel», seres imaginarios que parecen reales; «Romeo» ante el alquimista; «Uulieta» con su nodriza, «Ofelia» tirándose al agua; en fin, todas las figuras que el arte creó, y la humanidad entera ha hecho suyas, reconociéndolas como de su propia sustancia» (1894: 14).

Enumeración que pone de manifiesto no sólo el sólido conocimiento que Galdós poseía del poeta inglés, su familiaridad con sus personajes literarios, sino también su innegable admiración y reconocimiento. Atmósfera mágica, literaria, que le lleva hacia el pasado, pero que también impregna las impresiones de Galdós, atento observador, al reparar en los huéspedes que se hallan en el comedor del establecimiento hotelero, tipos que le parecen figuras inmortalizadas en las novelas de Dickens, de manera que mira expectante sus «piernas esperando ver en ellas las polainas de Mr. Picwick» (1894: 15) ${ }^{12}$. Galdós manifiesta su agrado por el confort y limpieza de este hotel que se asemeja a las hosterías descritas por Dickens en sus novelas o por Macaulay en sus descripciones de la vida inglesa. Encarece su abundante, aunque poco variada, comida y, sobre todo, el aseo de las habitaciones, dotadas de mullidas camas. Hotel familiar que se aleja por completo de las «magníficas colmenas para viajeros que en Londres se llaman el «Metropolitan» y en París el «Gran Hotel» (1894:13).

El tercer apartado de la crónica de viaje lo dedica Galdós a describir pormenorizadamente el espacio físico de la casa que compró Shakespeare en 1574. Galdós no duda en incluir todos los datos que pueden interesar a los posibles lectores, desde el precio que pagó el dramaturgo, cuarenta libras, hasta las vicisitudes sufridas. En 1847 fue comprada por los comités de Stratford y Londres y declarada monumento nacional. Situada en una de las principales y espaciosas calles de la localidad, contrasta con los edificios modernos,

12. Recuérdese que Galdós había publicado la traducción de Las aventuras de Picwick de Dickens en el periódico madrileño La Nación, 9 de marzo a 8 de julio de 1868.

Anales, 24, 2012, pp. 181-193 
por su estructura normanda, con ensamblajes de manera ennegrecida por el trascurso del tiempo. Galdós recorre la vivienda de dos pisos, observando las muestras de admiración que dejaron viajeros ilustres grabadas en las vidrieras verdosas que la adornan -Walter Scott, Dickens, Goethe, Byron, entre otras celebridades-. Se detiene ante el retrato del dramaturgo y fija largamente su atención en las piezas que más íntimamente están relacionadas con el mismo y que se conservan en un pequeño museo anexo a la casa: originales de contratos, ejemplares de las primeras ediciones de sus dramas, utensilios domésticos, un anillo marcado con las iniciales del poeta... El Museo le interesa vivamente y le conmueve, pero reconoce que la emoción más honda la experimentó ante la inmensa chimenea de campana que preside la cocina y que se adorna a un lado y otro de dos asientos o poyos de mampostería:

Cuantos hemos tenido la dicha de penetrar en aquel lugar, que no vacilo en llamar augusto, nos hemos sentado un ratito en donde el dramaturgo pasaba largas horas de las noches de invierno contemplando las llamas del hogar, que sin duda evocaban en su ardiente fantasía las imágenes que supo después reducir a forma poética con una maestría no igualada por ningún mortal (1894: 17-18).

Galdós ensalza el cuidado, orden y organización que observa en este monumento nacional inglés, pues se percata de que, incluso, los detalles más nimios están destinados a ensalzar la figura del dramaturgo que tanto honró a su patria. Así, el viajero puede contemplar en el jardín que rodea la casa las mismas flores y arbustos que más comúnmente son citados por el poeta en sus inmortales escenas y sonetos. El recorrido sentimental por los lugares ligados a la memoria de Shakespeare continúa con la visita al lugar donde se hallaba la casa en la que murió el mismo, derruida «bárbaramente a mediados del pasado siglo por el poseedor de la finca, sir J. Gastrell, cuyo nombre ha pasado a la posteridad por este acto de salvajismo» (1894: 20). Galdós informa a sus lectores de que este acto fue llevado a cabo por las molestias que le ocasionaban las continuas visitas de todos aquellos que rendían tributo de admiración al dramaturgo. En la actualidad tal desaguisado que atenta contra la memoria del Shakespeare se ha paliado con la construcción de un pequeño museo y un jardín «lleno de la memoria, y de las huellas, y de las sombras de aquel a quien Ben Johnson llamó alma del siglo, asombro de la escena» (1894: 20).

La última parte de la crónica la dedica el escritor a ensalzar la tradicional costumbre del país inglés de venerar los restos de sus hombres eminentes. Los de Shakesperare reposan en la iglesia parroquial de Stratford. La bellísima iglesia de estilo ojival es descrita con todo lujo de detalles: su gran nave con crucero, sus dos capillas colaterales pequeñas, la torre del siglo XIV que 
se alza sobre el crucero, etc. Galdós señala que su interior difiere de la desnudez árida propia de los templos protestantes por la variedad de elementos ornamentales con que está adornada, como sus rasgados ventanales de estilo inglés, el altar con gallardas esculturas, la sillería de nogal hábilmente tallado, los púlpitos y sepulcros ofrecen al viajero un conjunto de «extraordinaria belleza y poesía» (1894: 22). Galdós señala que al entrar en el santuario, todas las miradas de los visitantes se dirigen hacia el lugar donde se encuentra el monumento del dramaturgo en la pared norte del presbiterio. Se trata de un retablo «y quien no supiera qué imagen es aquella, la tomaría por efigie de un santo puesto allí para que le adoraran los fieles» (1894: 22). El cronista se detiene en la descripción del retablo, señalando la sensación de naturalidad que emana del mismo. El visitante contempla, sobresaliendo del retablo, la imagen de medio cuerpo de Shakespeare, cuyos brazos recaen con naturalidad sobre un cojín. En su mano derecha sostiene una pluma y la izquierda se apoya sobre un papel. Galdós subraya que la expresión noble de su rostro causa un impacto emocional a todos aquellos que lo contemplan: «Imposible apartar los ojos de aquella imagen, en que por un efecto de fascinación, propio del lugar, creemos ver al dramático insigne vivo y con la palabra en los labios» (1894: 23). Fascinado por el lugar, por el ambiente que se respira en la Trinity Church, Galdós describe la impresión mística, la comunicación espiritual, que siente en su ánimo, similar a la que experimenta una persona devota ante la contemplación de símbolos sagrados:

El entusiasmo literario y la fanática admiración que las obras de un ingenio superior despiertan en nosotros, llegan a tomar en tal sitio y ante aquella tumba el carácter de fervor religioso, que aviva nuestra imaginación, sutiliza y trastorna nuestros sentidos y nos lleva a compenetrarnos con el espíritu del ser allí representado, y a sentirle dentro de nosotros mismos, cual si lo absorbiéramos en virtud de una misteriosa comunicación (1894: 25).

El espacio se configura como lugar sagrado, no sólo por pertenecer a una iglesia consagrada al culto, sino por encontrarse en él los restos del poeta. Galdós no alude en ningún momento a la fe religiosa de los visitantes, sino que contempla el recinto como un nuevo templo pagano en el que se venera al «dramaturgo más grande que han producido los siglos» (1894: 28). El novelista ha alcanzado la meta de su peregrinaje y su espíritu parece conmocionarse profundamente. Su lenguaje, plagado de términos y símbolos religiosos, transmite con nitidez sus emociones y sentimientos. Para Galdós el espacio e individuo se asimilan en perfecta armonía, pues «aquel interior es digno de encerrar la memoria y los restos mortales del más gran dramaturgo del mundo, que en aquel recinto duerme su genio con un reposo que no es 
el de la muerte» (1894: 25). Espacio idóneo para que cualquier persona que posea un mínimo de tacto o delicadeza espiritual pueda experimentar, como él mismo comprueba, «emociones profundísimas, imaginando que conoce a Shakespeare, y se connaturaliza con él más estrechamente que leyendo sus obras» (1894: 25).

El clímax emocional va descendiendo en las últimas páginas de la crónica del viaje realizado por Galdós en 1889. La visita a otros lugares vinculados a la existencia de Shakespeare en Stratford cierra el viaje físico y epiritual del novelista español. Así, por ejemplo, rememora en el relato la visita a la Grammar School, donde el dramaturgo recibió la primera enseñanza o a la Guildshall, donde, según la tradición, los cómicos errantes que llegaban a Stratford daban sus funciones dramáticas. Lugar en el que con toda probabilidad Shakespeare vio las primeras representaciones escénicas que despertarían su genio creador. Los monumentos modernos consagrados a honrar la memoria del hijo más ilustre de la localidad no agradan en demasía a Galdós. La Clock Tower, de estilo gótico, le parece una construcción más severa que elegante y de proporciones no muy grandiosas, mientras que el Shakespeare Memorial Building se asemeja a un depósito comercial. La ventaja del segundo sobre el primero la percibe Galdós en los beneficios que proporciona, pues el Shakespeare Memorial alberga en su seno un teatro, un museo y una biblioteca. Especialmente atractivo le resulta la gran sala del teatro, donde «con frecuencia se representan por los mejores actores ingleses los dramas del sublime hijo de Stratford» (1894: 27) y la estatua en bronce ubicada en el agradable jardín que rodea el Shakespeare Memorial, estatua decorada con cuatro figuras representando a Lady Macbeth, Hamlet, Falstaff y el príncipe Hal, es decir, los cuatro caracteres fundamentales de la creación shakesperiana -el trágico, el filósofo, el cómico y el histórico-. Vasto edificio, en definitiva, que erigido por suscripción popular, honra a sus paisanos y es prueba irrefutable de su refinada cultura, en el sentir de Galdós.

El viaje físico y emocional de Galdós ha concluido. Viaje ardientemente deseado, tal como él mismo confiesa en las primeras líneas de la crónica: «En cuantas visitas hice a Inglaterra me atormentaron las ansias de ver la gloriosa villa... Una vez por falta de tiempo, otra por rigores del clima, ello es que no puede realizar mi deseo hasta el pasado año [1889]» (1894: 5). Galdós plasmará en esta crónica la turbación íntima experimentada al pisar el suelo, «que no vacilo en llamar sagrado» (1894: 5), donde nació y murió su admirado Shakespeare. Galdós no duda en unir la figura del dramaturgo con el lugar en que vivió, afirmando rotundamente que «no hay en Europa sitio alguno de peregrinación que ofrezca más interés ni que produzca emociones tan hondas, contribuyendo a ello, no sólo la grandeza literaria del personaje, a cuya 
memoria se rinde culto, sino también la belleza y poesía incomparables de la localidad» (1894: 5). Espacio urbano y literatura hermanadas a través del genio universal de William Shakespeare.

\section{BIBLIOGRAFÍA}

Berkowitz, H. Chonon, Pérez Galdós. Spanish Liberal Crusader, Madison, The University of Wisconsin Press, 1989.

Franco Rodríguez, José, En tiempos de Alfonso XII, Madrid, Renacimiento, s.a. Hernández SuÁrez, Manuel, Bibliografía de Galdós, Las Palmas, Cabildo Insular de Gran Canaria, 1972.

Nuez, Sebastián de la, Biblioteca y archivo de la Casa-Museo Pérez Galdós, Las Palmas, Cabildo Insular de Gran Canaria, 1990.

NuEz, Sebastián de la y José Schraibman, Cartas del Archivo de Galdós, Madrid, Taurus, 1967.

ORTIZ-ARMENGOL, Pedro, De como llego a Inglaterra. -Y a quien, y a donde- el primer ejemplar de «Fortunata y Jacinta», enviado por su autor, Madrid, Imprenta El Arte, 1981.

Ortiz-Armengol, Pedro, Vida de Galdós, Barcelona, Crítica, 1996.

PÉREZ GALDÓs, Benito, «Stratford-on-Avon. The home of Shakespeare», El Imparcial, 28 de mayo, 4, 11 y 18 de junio de 1894.

Pérez Galdós, Benito, La casa de Shakespeare. Portugal. De vuelta a Italia, Barcelona, Antonio López, Editor, «Colección Diamante», s. a. [1894].

PÉrez Galdós, Benito, «La casa de Shakespeare», en Memoranda. Paco Navarro. La Reina Isabel. La casa de Shakespeare. Pereda. Cuarenta leguas por Cantabria. Clarín. Ferreras. Don Ramón de la Cruz y su época. Niñerías. Soñemos, alma, soñemos. Rura. ¿Más paciencia? La República de las Letras, Madrid, Perlado, Páez y Compañía (Sucesores de Hernando), 1906, pp. 35-57.

PÉREZ Galdós, Benito, «La casa de Shakespeare», en Obras Completas. Novelas y Miscelánea, Federico Carlos Sainz de Robles (ed.), Madrid, Aguilar, 1973, pp. 1196-1202.

PÉReZ Galdós, Benito, Memorias de un desmemoriado, en Obras Completas. Novelas y Miscelánea, Federico Carlos Sainz de Robles (ed.), Madrid, Aguilar, 1973, pp. 1430-1473.

PÉrez Galdós, Benito, La casa de Shakespeare, Madrid, Rey Lear, 2007.

Shoemaker, William H., Las cartas desconocidas de Galdós en «La Prensa» de Buenos Aires, Madrid, Ediciones Cultura Hispánica, 1973.

www.lascartasdeperezgaldos.es

Fecha de recepción: 20-1-2012

Fecha de aceptación: 30-4-2012 